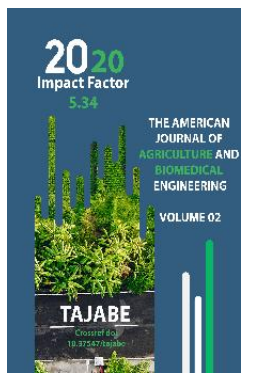

Journal Website:

http://usajournalshub.c

om/index,php/tajabe

Copyright: Original content from this work may be used under the terms of the creative commons attributes 4.0 licence.

\section{Trichogram Reproduction On Cotton Scoop Eggs In Biolaboratory}

\author{
Kh.Kimsanbaev \\ Tashkent State Agrarian University, Tashkent, Uzbekistan. \\ M.Urazmetov \\ Tashkent State Agrarian University, Tashkent, Uzbekistan. \\ R.Jumaev \\ Tashkent State Agrarian University, Tashkent, Uzbekistan.
}

\title{
ABSTRACT
}

The article discusses the issue of mass reproduction in the biological laboratory of the ovarian parasite of Lepidoptera - Trichogramma, in particular the species Trichogramma evanescens Wes, widely represented in the nature of Uzbekistan. against the dangerous pest of cotton bollworm. In Uzbekistan, much attention is paid to the use of a biological method, in particular entomophages, which, unlike the chemical method, is characterized by safety for the environment and high biological efficiency reaching 69-75\%. The article describes the technology of reproduction of trichogramma in a biological laboratory on eggs natural hosts of the entomophage.

\section{KEYWORDS}

Biological method, biolaboratory, cotton scoop, trichogramma, mother material, sitotrog, biological efficiency, entomophage dispersal, reproduction technology.

\section{INTRODUCTION}

The boxworm, the larva of the cotton bollworm (Heliothis armigera Hb.) Damages the flowers, buds and bolls of cotton, as well as corn cobs, tomato fruits, pea kernels and many other crops. Affected buds and young cotton bolls fall off, which greatly affects the overall yield.

In the conditions of Central Asia and the Caucasus, the first mass year of butterflies coincides with the time of the formation of 
cotton ovaries and falls on average from May 20 to June 20. With average monthly temperatures equal to $200 \mathrm{C}$, the development of the pest takes 43-44 days, with an increase in temperature to 300 it is reduced to 30 days.

Various methods are currently used to combat box worms, in particular, agrotechnical, chemical and others. Farmers in Uzbekistan widely use the biological method, which has proven to be highly effective and is the most economically viable.

The main natural enemies of the cotton bollworm from parasitic organisms are: trichogramma, apanteles, microplateis, macrocentrus, barilipa, bunchus, ambliteles, tahina flies and some other representatives of the insect world. In total, more than 45 species of naturally inhabiting hymenoptera parasites of the cotton bollworm and 10 species of takhin flies are known in the cotton growing regions.

\section{MATERIALS AND METHODS}

In the system of protection of the cotton crop, great importance is attached to the parasite - the egg-eater of the Trichogramma pintoi species, in particular the species T.evanescens Wes, widely represented in the nature of Uzbekistan, which belongs to the representatives of the family. Trichogrammatidae, order Hymenoptera. Insects belonging to this family of chalcides, despite their small size 0.12-1.2 mm, are considered ovarian parasites of scoops, moths and many other harmful lepidoptera pests, because develop inside their eggs. Unlike larvae, adults feed on the nectar of flowers.

Trichogramma hibernates in the phase of adult larvae in the eggs of various lepidoptera pests, where it later turns into a pupa and then, gnawing through the shell, flies out in the form of an imago. After mating, begins to lay eggs.

Trichogramma evanescens Westw are small insects (0.4-0.6 mm), light brown to black. The forewings are wide with cilia, 2 times as long as the wing width. Males are similar to females, only the antennae of the female are 5-segmented, in contrast to the 3-segmented antennae of the male.

In agrobiocenoses, they are found on crops of cotton, corn, tomatoes, cabbage, beets and other crops. It is considered one of the main entomophages in the protection of crops from harmful butterflies, because guided by the smell of the pest, it lays 1-2 of its eggs in the eggs of the pests, in which it develops further by feeding on the internal contents.

On average, one female can lay 45-60 eggs. Biological efficiency is $69-75 \%$. The optimal conditions for development are: temperature in the range of $20-330 \mathrm{C}$ with a relative humidity of $75-90 \%$. In the population, the number of females is greater and amounts to 75-90\%. In the conditions of Uzbekistan, it gives 10-12 generations.

An adult insect lives on average 4-6 days, when the temperature drops to $10-110 \mathrm{C}$, it hibernates.

\section{TRICHOGRAMMA}

REPRODUCTION TECHNOLOGY IN THE BIOLABORATORY

According to the proven technology, in order to obtain the required quantity of high-quality products of the trichogram under the conditions of artificial reproduction in biolaboratories, it is necessary to have a supply of mother material. Mother material includes biological material collected in nature, which includes the collection of scoop eggs infected with trichogramma. Collection of mother material begins in August and 
continues until January-February. The production of mother material includes separate stages:

1. Collecting natural trichogramma in the fields.

2. Growing scoop eggs.

3. Cultivation of Trichogramma mother material.

4. Entering the grown trichogramma into diapause.

Growing eggs of scoops - natural hosts of trichogramma. To obtain the mother material of Trichogramma, it is necessary to pass it through cultivation in a biological laboratory in the eggs of natural hosts in the autumn and winter periods. (fig. 1). (Kimsanbaev Kh.Kh.).

To obtain pest eggs, butterflies or scoop pupae collected in nature by various methods (for example, by light traps) are grown in a biological laboratory. One of the directions of obtaining eggs from butterflies of natural hosts is their breeding and reproduction in a biological laboratory in artificial or natural environments.

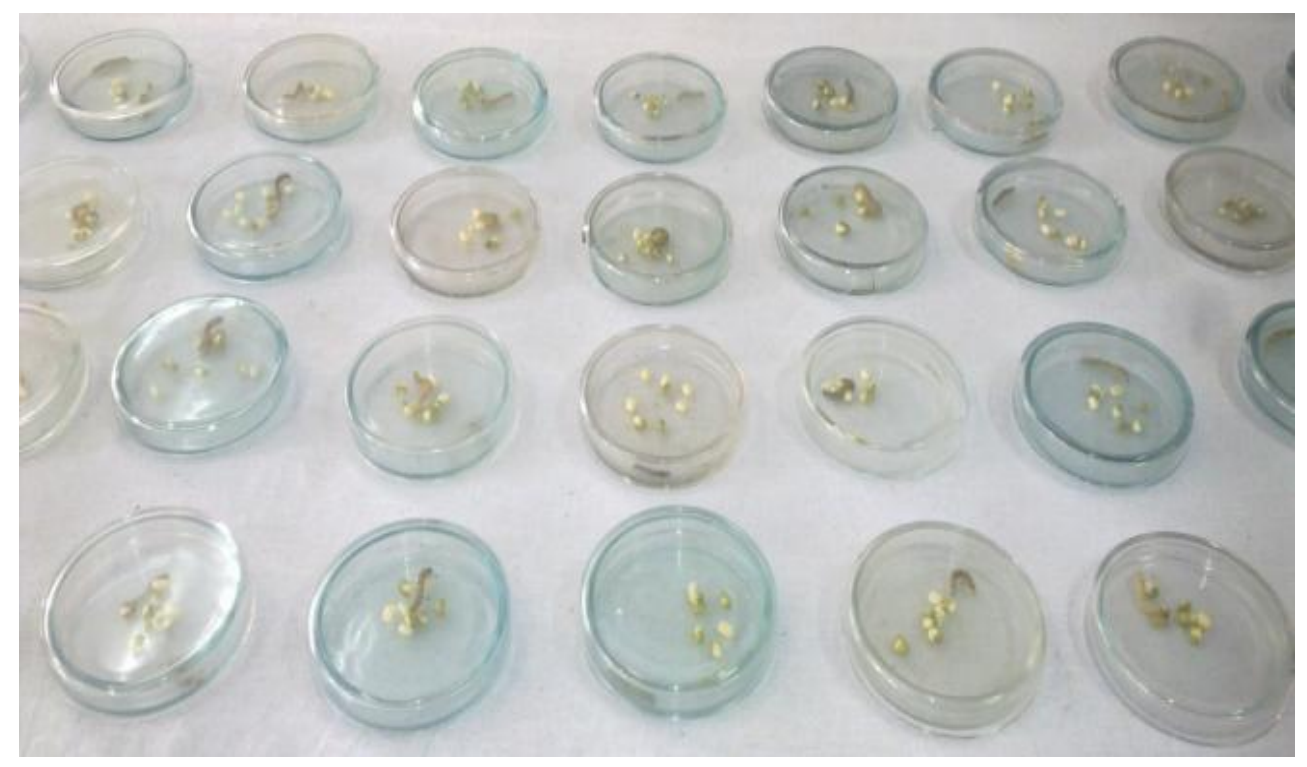

Fig. 1. Mass breeding of butterflies scoop in a laboratory.

To do this, males and females of scoop butterflies collected in nature are mixed in glass containers of 8-10 individuals. To collect further pest eggs, accordion-folded paper is laid inside the jar. To feed the butterflies, a cotton wool soaked in $20 \%$ sugar syrup is placed on the bottom of the can. Banks are covered with gauze, which is fixed with a rubber ring. Banks are stored at a temperature of $20-250 \mathrm{C}$ and a relative humidity of $65-70 \%$. Banks are reviewed daily with the collection of laid eggs and deceased individuals, which are replaced with fresh ones.

Obtaining Trichogramma mother material from scoop eggs. Trichogramma collected in nature is stored in a wide-necked 1 liter glass container covered with a dense cloth on top. To feed the trichogramma, a cotton wool 
soaked in $10 \%$ sugar syrup is placed on top of the fabric. The grown eggs of natural hosts are laid inside. When the ratio of males and females is 1:20, mating occurs. Banks are stored in the light at a temperature of $24-250 \mathrm{C}$ and a relative humidity of $70-75 \%$ (Kh.Kh. Kimsanbaev, 2007).
After 5-7 days, the infected eggs turn black and are laid out from the container, replacing them with new, uninfected eggs. The change of lots of eggs is carried out 3-4 times. Thus, the uterine population of Trichogramma is obtained.

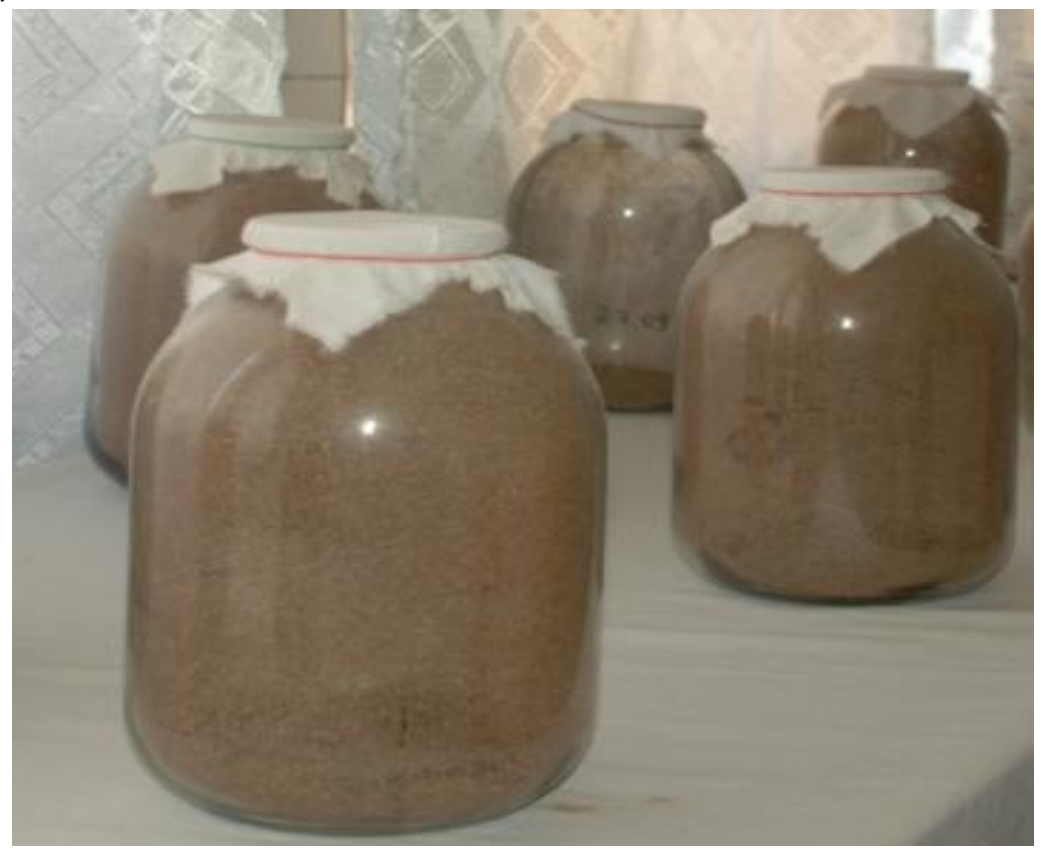

Figure: 2. Bulk rearing of eggs in the laboratory grain moth infected with trichogramma

\section{RESULT AND DISCUSSION}

\section{Obtaining a commercial trichogram}

Obtained from the uterine population in a massive way in the biolaboratory, the trichogram is the final product and is used in crops to control harmful Lepidoptera.

The mother material of the Trichogramma in the biolaboratory is propagated for 4-5 cycles on the eggs of the grain moth (sitotrogi).

For withdrawal from diapause, 2-3 $\mathrm{g}$ of Trichogramma stored in the refrigerator is placed in glass jars, which are stored at a temperature of $25-260 \mathrm{C}$ and a humidity of 75 $80 \%$. After 3-6 days, the trichogramma years begins. To feed the trichogramma, a cotton swab soaked in $20 \%$ sugar syrup is placed on top of the cloth covering the can.

To obtain a commercial trichogram, it is necessary to cultivate it on the eggs of a laboratory host of a grain moth. To do this, the cleaned 3 I jars are "steamed" and dried, then in a circular motion the jars are laid inside the jars grown in the biolaboratory. Then on the eggs of the grain moth adhered inside the jar, the mother material of the Trichogramma is released. The banks indicate the number of eggs laid by the sitotroga and the released trichogramma. Lighting is required to obtain a commercial trichogram.

After 5-6 days, the eggs of the grain moth, embedded inside the jar, infected with 
trichogramma, darken and with a soft brush are collected in paper bags indicating the collected mass.

If it is impossible to immediately use sitotrogi eggs on crops infected with trichogramma, they can be stored for a short time in household refrigerators at a temperature of 1$30 \mathrm{C}$ and a humidity of $80-90 \%$.

\section{Trichogramma application}

For highly effective use of the commercial trichogram obtained in the biolaboratory, it is necessary to observe the technology of its reproduction. So, in the trichogramma production shop, the temperature should be kept within $25-300 \mathrm{C}$ during the day, $18-200 \mathrm{C}$ at night with a humidity of $60-70 \%$. Trichogramma is fed daily with $20 \%$ sugar syrup, occasionally supplemented with pure water.

The first dispersal of Trichogramma in the fields coincides with the moment of laying eggs by pests. The terms of colonization are determined according to long-term forecasts and on the basis of data on the number determined by pheromone traps.

Infection of cotton bollworm eggs in the field is observed after 5-8 days. After 10-12 days, the effectiveness of infection of the pest's eggs is reduced by 4 times, and after 15 days, it is not observed at all. Consequently, for effective protection of the crop, a 3 -fold release of the entomophage biomaterial is required. So, 0.5 $+0.75+0.5 \mathrm{~g}$ (or $30+50+30$ thousand pieces) of trichogramma are settled per 1 hectare, for cotton crops the ratio is $60+80+60$ thousand pieces (total 200 thousand).

\section{CONCLUSION}

The first colonization with trichogramma is carried out after 5-6 days when pheromone traps detect 2-3 butterflies of the cotton bollworm per day. The second and third time 3-4 days after detecting 1.2 moths per day. It is necessary to pay attention to the uniform distribution of the biomaterial. To do this, trichograms, ready to emerge from the infected eggs of the grain moth, are laid out in 2 or $3 \mathrm{I}$ jars, then 100 pieces are placed there. folded $1-1.5 \mathrm{~cm}$ of scraps of paper on which emerged individuals of the entomophage settle.

Trichogramma is released early in the morning (at 6-11 o'clock), or in the evening (from 18-20 o'clock) on the shaded leaves of the lower or middle tier of plants. For 1 gatrichogram, it is settled in 100 places (according to the scheme $10 \times 10 \mathrm{~cm}$ ).

\section{REFERENCES}

1. Kimsanboev X.X., Anorbaev A.R., Jumaev R.A. Technology of growing trichogram in artificial nutrient media in biolaboratories // Bulletin of the National University of Uzbekistan. № 3/2. Tashkent. 2016. -P 1215.

2. Sulaymonov B.A., Kimsanboev X.X., R.A. Jumaev., A.A. Rustamov., A.R. Anarbaev., O.A. Sulaymonov. Biological protection of plants. Tashkent-2015. . -P. 10-158.

3. Sulaymonov B.A., Kimsanboev X.X., Jumaev R.A., Rustamov A.A., Anorbaev A.R., Sulaymonov O.A., Esonboev Sh. Artificial feed for trichogramma growth // Official Bulletin of the Intellectual Property Agency. №3 (167). №IAP 0052. Tashkent, 2015. -P. 7.

4. Sulaimonov B.A., Anorbaev A.R. Trichogramma regulation of the number of Lepidoptera in corn // Conceptual and applied aspects of scientific research and education in the field of invertebrate zoology. Collection of materials of the IV 
International conference. Tomsk, 2015 ---

P. 12-15.

5. Firempong, S. \& Zalucki, M.P. Host plant preferences of populations of Helicoverpa armigera (Hübner) (Lepidoptera: Noctuidae) from different geographic locations. Australian Journal of Zoology. -1990.N37. -P.665-673.

6. Flanders S.E. The mass production of Trichogramma Minutum Riley and artificial parasitum of the codling moth ess || Intern longr. Entomol. 4th , Jtnace, 1928. Transoct. -1929. -Vol 2. -P. 110-130.

7. Ishii I. The species of Trichogramma in Japan, with descriptions of two new species. -Kontyu 14. -1941. -P. 169-176.

8. Murray D. A. H., Rynne K. P., Winterton S. L. , Bean J. A., Lloyd R. J. Effect of Host Plant on Parasitism of Helicoverpa armigera (Hübner) (Lepidoptera: Noctuidae) by Hyposoter didymator Thunberg (Hymenoptera: Ichneumonidae) and Cotesia kazak (Telenga) (Hymenoptera: Braconidae). Australian Journal of Entomology. Volume. 34, Issue 1. -2004. -P. 71-73. 